\title{
Selection of Viscous Coolants in Granite Machining
}

\author{
B.Nageswara Rao ${ }^{1}$, Dr.Jeb.Nelson ${ }^{2}$, Dr.B.Balunaik ${ }^{3}$, Director, Paul Raj ${ }^{4}$ \\ 1, 2, 3, BITS/ME, Khammam, A.P., India, .Deputy Director, academic staff college jntu Hyderabad \\ ${ }^{4}$ Engineering College Bhadrachalam, Khammam, AP. Deputy Director,academic staff college jntu Hyderabad
}

\begin{abstract}
In granite machining operation mainly the coolants used are viscous based coolants either kerosene, soluble mineral lard oil and water based coolants. By using water based coolants or solvents get maximum economy or less production cost than other coolants used in granite machining operation. While machining due to contact surfaces between granite block and cutting tool automatically there will be produce high heat due to high temperature cause, therefore the tool life may reduce surely. Hence there will be a minimum tool life, irregular finish of the cutting pieces and won't get dimensional accuracy. Material, due to increase in maximum heat. So everybody can use viscous lubricants in machining process that will give a cooling effect among the work piece, cutting tool and chip. Due to this result in machining get continuous chip without built up edge and also get maximum tool life because of low temperature produced at the cutting zone. Due to this low temperature also get accurate dimensions of the product. They are used to provide lubrication and cooling effects between cutting tool and raw block and chip during granite machining operation. Hence the influence of generated heat on cutting tool would be prevented as a result cutting fluids are used in granite machining for variety of reasons such as improving tool life, reducing work piece thermal deformation, improving surface finish and flushing away chips from the cutting zone. Choosing of viscous coolants depends on the type of raw blocks, cutting tool material and type of machining process.
\end{abstract}

Keywords: Machining; Tool materials; coolants; rough granite blocks; chips; accuracy;

\section{Introduction}

The aim of coolants using in granite machining are 1. To reduce the heat produced at cutting zone due to high cutting speed. 2. To cool and clean the work piece, cutting tool and to keep the chip away from the cutting point properly. 3. Using viscous lubricants to protect the machined surface from rust and corrosion effect. Also by using cutting fluids in machining include reduced thermal deformation of work piece better surface finish machining processes have an important place in the traditional production industry. 4 . By using viscous lubricants have to reduce the protection cost as well as to minimize the production time taken to cut the work piece. And also get high production rates with better surface finish. This is mainly affected selection of suitable machining parameters like cutting speed, feed rate and depth of cut according to cutting tool and work piece material. finish and higher material removal rate.

In this study, the studies about cutting fluid application in granite machining processes have been evaluated. The selection criteria of cutting fluids have been examined. Suitable cutting fluids for various material machining processes have been determined according to cutting tool materials.

\section{Coolant Selection Criteria}

Principle criteria for selection of cutting fluid for a given machining operation are

1. Process performance

a).Heat transfer performance b).Lubrication performance c).Chip flushing

d).fluid mist generation e).Fluid carry off in chips f).Corrosion inhibition

g).Fluid stability

2. Cost performance

3. Environmental performance

4. Health hazard performance

For cutting generally a fluid having high viscosity is used. It cools the temperature raised in the process of cutting. It is an important parameter. The process of reduction in temperature is a must so that the life of the tool can be enhanced. These viscous fluids will keep the shape of the tool in tact because of low wear due to friction and the efficiency of the tool can be improved. While cutting the rake face of the cutting tool remains as it is due to lubricants. The chips move away from the tool in the process cutting due liquids.

If the lubrication is less more number of chips are released. So lubrication reduces built-up edge to less area in some materials.

This system of working produces more roughness to the rake. 


\section{Selection Of Suitable Coolants}

The selection of $\mathrm{cutting}$ fluids in $\mathrm{machining}$ processes depends on various factors. The selection of cutting fluids is carried out according to factors mentioned below

a) Type of machining process

b) Type of machined work piece material

c) Type of cutting tool material

\subsection{Type of machining processes}

The most important parameter in the selection of cutting fluids is the characteristics of machining process. Variety of machining processes would indicate relation between work piece materialcutting tool-chip combinations. The most difficult machining process will need to use more cutting fluid. The excellent literature survey in cutting fluids application provided same important data; machining processes were put in order according to the amount of usable cutting fluids quantity from the smallest amount to the highest amount.

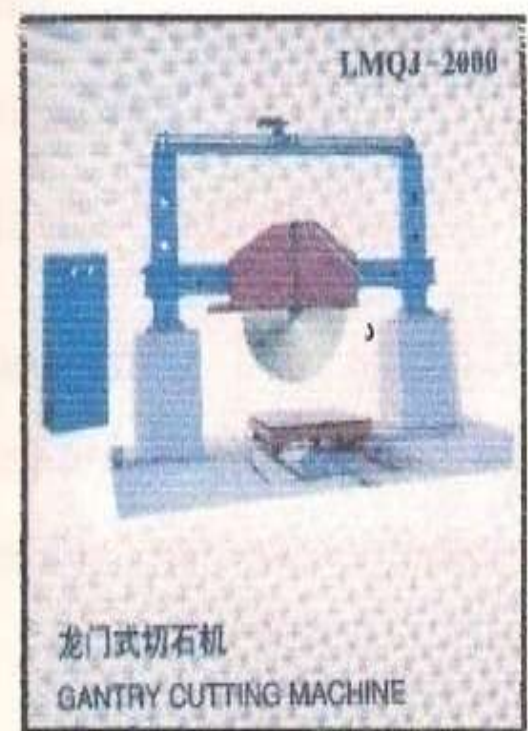

Figure 1 Granite Cutting Machine

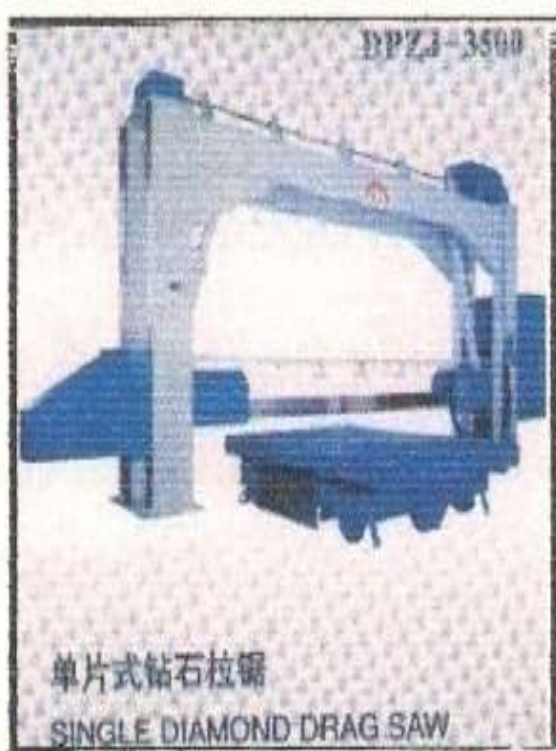

Figure 2 Granite Cutting Machine

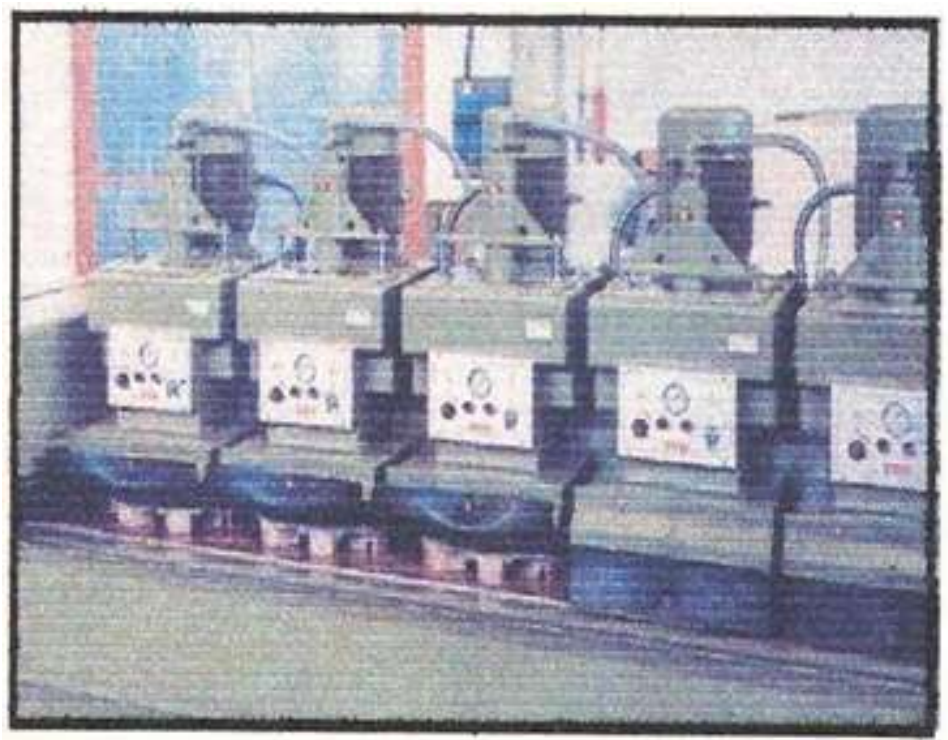

Figure 3 Autopolisher:

\subsection{Work piece materials}

The other factor for selection of suitable coolants in machining processes is the type of work piece material. The application of cutting fluids should provide easy machining operation in 
all materials. The cutting fluid is encountered widespread in engineering applications will be determined at below.

\subsection{Cutting tool materials:}

The third influential parameter for selection of cutting fluid in machining processes is the cutting tool material. Various cutting tool materials are commercially available for all kind of machining processes.

High speed steel cutting tools can be used with all type of cutting fluids. However waterless cutting fluids are preferred when difficult-to-cut materials are machined.

\section{Machining On 1.6 - Meter Dia Blade Machine:}

4.1.1-1.6 - Meter dia blade machine is used for cutting hard rough block and soft bond diamond tool. The spindle speed is fixed at $380 \mathrm{rpm}$. The cut piece size is $3^{\prime} \times 1^{\prime}$. Using three coolants of water, \{water+ oil\}, \{ water + nirma $\}$, The experiments are conducted and the following results are obtained.

\section{1: Machining Hard Rough Block Using Hard Bond Diamond Tool:}

1.6- Meter diamond machine is used for hard rough block using hard bond diamond tool. The spindle speed is fixed at $380 \mathrm{rpm}$. The cut piece size is 3'x1'. Using three coolants of, water+oil, water+oil,water+oil+nirma, The experiments are conducted and the following results are obtained which are shown in table 1 to table 3

TABLE 1 Water as Colant

\begin{tabular}{|l|l|l|l|}
\hline S.No. & Time consumed (min) & Power consumed (KWH) & $\begin{array}{l}\text { Tool } \\
\text { Consumption mm }\end{array}$ \\
\hline 1. & 5 & 2.7 & \\
2. & 10 & 3.1 & \\
3. & 15 & 3.5 & 0.6 \\
4. & 20 & 3.9 & \\
5. & 25 & 4.3 & \\
6. & 30 & 4.7 & \\
7. & 35 & 5.2 & \\
8. & 36 & 5.3 & \\
\hline
\end{tabular}

Table - 2: (water +oil) as coolant

\begin{tabular}{|l|l|l|l|}
\hline S.No. & Time consumed $(\mathrm{min})$ & Power consumed $(\mathrm{KWH})$ & $\begin{array}{l}\text { Tool } \\
\text { Consumption mm }\end{array}$ \\
\hline $\mathbf{1 .}$ & & 2.5 units & \\
$\mathbf{2 .}$ & 10 & 2.9 & \\
$\mathbf{3 .}$ & 15 & 3.3 & $\mathbf{0 . 5}$ \\
$\mathbf{4 .}$ & 20 & 3.7 & \\
$\mathbf{5 .}$ & 25 & 4.0 & \\
$\mathbf{6 .}$ & 30 & 4.3 & \\
$\mathbf{7 .}$ & 32 & 4.7 & \\
\hline
\end{tabular}

Table 3 coolant as (water+oil)

\begin{tabular}{|l|l|l|l|}
\hline S.No. & Time consumed $(\mathrm{min})$ & Power consumed $(\mathrm{KWH})$ & $\begin{array}{l}\text { Tool } \\
\text { Consumption mm }\end{array}$ \\
\hline $\mathbf{1 .}$ & $\mathbf{5}$ & 2.3 & \\
$\mathbf{2 .}$ & $\mathbf{1 0}$ & 2.7 & \\
$\mathbf{3 .}$ & $\mathbf{1 5}$ & 3.0 & $\mathbf{0 . 4}$ \\
$\mathbf{4 .}$ & $\mathbf{2 0}$ & 3.4 & \\
$\mathbf{5 .}$ & $\mathbf{2 5}$ & 3.8 & \\
$\mathbf{6 .}$ & $\mathbf{3 0}$ & 4.0 & \\
$\mathbf{7 .}$ & $\mathbf{3 1}$ & 4.4 & \\
\hline
\end{tabular}

Graph is drawn for the above results on X-Y plot and is shown in figure 4 


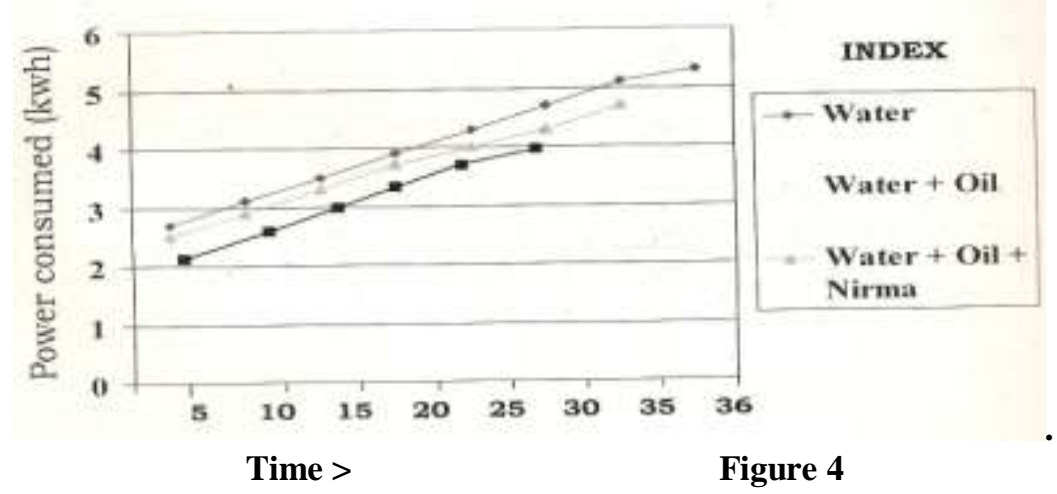

Fig 4. Performance curve for various coolants used during machining of HRB using HBDT on 1.6-meter Dia Blade Machine From the above experimental results, it is observed that

1) The tool life is $0.6 \mathrm{~mm}$ when the coolant is water $0.5 \mathrm{~mm}$ when the coolant is (water+oil) and $0.4 \mathrm{~mm}$ when the coolant is (water+oil+nirma) The tool life is increased; when the coolant is (water+oil+nirma) as compared to (water+oil).the tool life is also high when the coolant is (water+oil) as compared to water only.

2) The time taken is 36 min to cut the piece when the coolant is water and 32 min in case of (water+oil) and 31 min incase (water+oil+nirma). Hence time taken to cut piece is in the decreasing order, when the coolant are water ,(water+oil) and (water+oil+nirma)

3) The power consumed is $5.3 \mathrm{KWH}$ in case of water as coolant and $4.7 \mathrm{KWH}$ when the coolant is (water+oil) and 4.4 KWH when the coolant is (water+oil+nirma). Hence the power is considerably reduced when the coolant is (water+oil+nirma) as compared to (water+oil).the power is also less when the coolant is(water+oil) as compared to water.

\section{Conclusions:}

The selection of coolants for granite process generally provides various benefits such as longer tool life, higher surface finish quality and better dimensional accuracy. These results also offer higher cutting speeds, feed rates and depths of cut. The productivity of machining process will be much higher with combination of selecting higher machining parameters. The material removal rates will be increased.

Therefore, selection of the most suitable cutting fluid in any machining process must be carried out to obtain a maximum benefit. The selection of suitable cutting fluid is affected by mainly three factors in machining operations. These are the types of machining process, workpiece materials and cutting tool materials. The combination of these three influential factors would provide basic information for selecting the suitable cutting fluid.

The regeneration methods of used cutting fluids would also provide various advantages such as reducing cutting the fluids cost, disposals cost of used cutting fluids and nearly eliminating environmental pollution.

Experiment s are observed by taking three type of cooling media Viz, water, $\{$ water +oil $\}$, $\{$ water + Nirma $\}$ and changing the other parameters like Hardness /Softness of Rough block and hard /soft cutting tool material.

The following conclusions are drawn from the experimental results

- The time taken to cut the rough blocks is low in high viscous coolants as compared by to low viscous hence is machining time can be reduced by using high viscous coolants.

- High viscous coolant result in low rubbing the power consumed is less as compared to low viscous coolants during machining hence the power can be saved by using high viscous coolants

The tool life is increased by using high viscous coolants

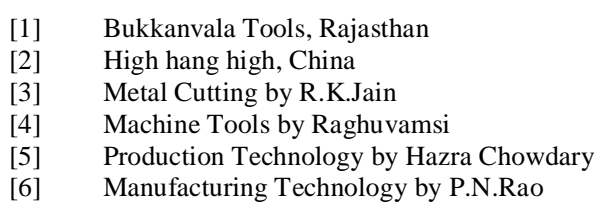

\section{References:}

